\title{
Hierarchical Criticality Analysis of Clean Technologies Applied to a Coal-Fired Power Plant
}

\author{
Andressa Padilha de Oliveira ${ }^{1}$, Giulio Lorenzini ${ }^{2 *}$, Zeban Shah $^{3}$, Marcos Antonio Klunk ${ }^{4}$, José Eduardo de Carvalho \\ Lima $^{4,5,6}$, Luiz Alberto Oliveira Rocha ${ }^{4,5}$, Nattan Roberto Caetano ${ }^{1}$ \\ ${ }^{1}$ Federal University of Santa Maria, Av. Roraima, 1000, Camobi, Santa Maria 97105-900, Rio Grande do Sul, Brazil \\ ${ }^{2}$ Dipartimento di Ingegneria e Architettura, Università di Parma, Parco Area delle Scienze 181/A, Parma 43124, Italy \\ ${ }^{3}$ Federal University of Rio Grande do Sul, Av. Bento Gonçalves, 9500, Porto Alegre, Rio Grande do Sul, Brazil \\ ${ }^{4}$ University of Vale do Rio dos Sinos, Av. Unisinos, 950, Cristo Rei, São Leopoldo 93022-000, Rio Grande do Sul, Brazil \\ ${ }^{5}$ Doctor Leão Sampaio University Center, Av. Padre Cícero, 2830, Triângulo, Juazeiro do Norte, Ceará, Brazil \\ ${ }^{6}$ Faculty of Paraiso do Ceará, Rua Conceição, 1228, São Miguel, Juazeiro do Norte 63010-465, Ceará, Brazil
}

Corresponding Author Email: giulio.lorenzini@unipr.it

https://doi.org/10.18280/ijdne.150501

Received: 11 June 2020

Accepted: 20 September 2020

\section{Keywords:}

mineral coal, combustion, clean technologies, thermoelectric power

\begin{abstract}
Mineral coal is the main source of energy generation in the world. In Brazil, this energy source has a smaller share in the internal energy supply, 5.5\% of the total. Despite this, issues of energy security, stable and low prices make coal a strategic source. Due to this source's importance, this work aims to evaluate the clean technologies used to mitigate the emission resulting from the combustion of coal from a thermoelectric plant that applies low quality coal in Brazil using an analytical hierarchy process to classify the viable technological alternatives for the production process. The articulation of the environmental management system was adequate to meet the environmental demands and the energy efficiency of the thermoelectric plant. However, the results suggest that the investment in a coal processing plant would increase the fuel quality, a critical factor in the reduction of operating milling costs, in the ash circuit, and the treatment of gaseous emissions.
\end{abstract}

\section{INTRODUCTION}

Greenhouse gas emissions are connected to several global economy areas, and the prevailing is the energy sector [1]. Gas emissions related to coal combustion are the single largest contributor to global climate change [2-5]. Coal accounted for $44 \%$ of the $33 \mathrm{GtCO}_{2}$ of global energy-related $\mathrm{CO}_{2}$ emissions in 2019, of which two-thirds came from the use of coal for electricity generation [6].

Resistance to a change in coal stems from various actors such as coal companies, unions, parts of civil society, and the government, albeit for different reasons. These actors and their coalitions deeply influence the policy results concerning coal production and consumption. In addition to politics, economic development and technological innovation are elements that have a strong influence on the definition of the energy matrix of a given country [7-10].

The second most important energy source worldwide is coal, contributing to $40 \%$ of global primary energy consumption [11]. The generation of thermal energy in the country has proved to be different from that practiced in most countries, where electricity production from heat predominates [12-14]. Brazil has a large coal reserve, whose resources are in the order of 32 billion tons, classified from sub-bituminous to highly volatile bituminous, and have a high ash yield and sulfur content [15].

Although Brazilian coal has low calorific value, the availability of reserves and the development of less polluting technologies suggest thermal generation as an excellent expansion potential [16-19].

The Brazilian electricity sector emitted an average of 101.3 $\mathrm{kg} \mathrm{CO}$ to produce $1 \mathrm{MWh}$, a low rate compared to the European Union, the United States of America, and China [20, 21]. The coal production chain has the challenge of guaranteeing its activities, by adapting the thermoelectric plants in operation to the clean technologies available, encouraging the application in future projects [22]. The difficulty lies in generating electricity safely and efficiently, maintaining the balance of natural resources with the Brazilian economic need [23].

This study evaluates the clean technologies developed in thermoelectric industries, aiming to mitigate the emission of pollutants to the atmosphere due to coal combustion. It presents a systematic approach through the analytical hierarchy process to classify viable technologies in the energy production process in a thermoelectric plant in southern Brazil.

The manuscript's relevance stems from the analysis that the low efficiency in the conversion of thermal energy is not only due to the use of lower-quality coal but also the conservation of old technologies. Moreover, adapting to clean technologies or replacing bottleneck units could improve energy conversion efficiency while also reducing gas emissions. Therefore, it is necessary to optimize the use and make it compatible with preserving the environment. 


\section{THEORETICAL TECHNOLOGIES USED TO MINIMIZE ATMOSPHERIC EMISSIONS}

Coal accounted for $41.1 \%$ of the 23.391 TWh of electricity generated globally, making it the primary source of electricity generation, surpassing the share of natural gas in the world's electricity matrix almost twice. The ore's projection is to hold a similar position over the next 30 years because fossil fuel has the highest availability in the world, and it guarantees enough to meet current production for 130 years [24]. Despite efforts to maintain the electrical matrix based predominantly on sources of low emission of greenhouse gases, the technical characteristics of the new hydroelectric and intermittent renewable sources such as wind and solar do not allow the sectorial planning to renounce the thermoelectric options of non-renewable sources. In this sense, mineral coal with competitive cost and characteristics that add reliability to the interconnected national system, integrated with technologies with less environmental impact, has proved to be a viable option for energy generation [14].

From the combustion efficiency, it is possible to verify that most Brazilian thermal plants are ancient and with inefficient burning technologies [25]. Conventional subcritical plants, the type most used in coal-fired power plants, including in Brazil, with an efficiency of up to $38 \%$, will continue to prevail in expanding the thermoelectric generator park on the horizon until $2025[14,26]$. This technology will lose its global share to more efficient low-emission technologies around 2030, including advances to ultra-critical cycles with efficiencies greater than $50 \%$ and carbon capture and storage (CCS) technologies until $2050[26,27]$.

The modernization of combustion systems can increase efficiency, with the consequent reduction in $\mathrm{CO}_{2}$ emissions and other pollutants, an alternative for maintaining fossil fuel use $[28,29]$. Technological advances towards sustainability are increasingly incremental, and many companies find it challenging to meet their sustainability goals. A range of options is available for removing $\mathrm{CO}_{2}$ emissions [30-32].

The essential technological routes concerning the use of coal as a fuel are pulverized mineral coal, supercritical and ultra-supercritical plants, fluidized bed combustion, and integrated gasification with combined cycle (IGCC). It is worth noting that the technology choice is not only based on efficiency but depends on many specific criteria associated with unit size, operating regime, and environmental legislation [33].

\subsection{Powdered mineral coal}

Powdered mineral coal is the most used technology for the combustion of mineral coal and generation of electric energy globally and represents more than $90 \%$ of the plants in operation [34]. This technology was developed in 1920 and consisted of reducing the size of the coal particles to be introduced into the boiler, where it is burned at high temperatures in the range of 1300 to $1700^{\circ} \mathrm{C}$, depending on the quality of the coal. As the firing is done in a pulverized form, there is an increase in efficiency due to the large surface area existing for the reaction $[14,34]$.

To be considered a clean-burning technology, it needs to be complemented by modern $\mathrm{NO}_{\mathrm{x}}$ control systems, gas desulfurization and particle removal, filters, and other impurity removal systems [35]. The efficiency of converting thermal energy into electricity can reach $43 \%$ in plants with a supercritical steam cycle. However, all Brazilian plants in operation and under construction use this technology in a subcritical cycle. They operate with an average efficiency of $33 \%$ to $35 \%[36]$.

\subsection{Supercritical and ultra-supercritical plants}

The ultra-critical and supercritical cycle technologies, also known as advanced pulverized coal technology, are powdered coal plants that operate at critical levels of temperature and pressure than traditional ones in search of more efficiency. The biggest problems with this technology are the high levels of pollutants and the fact that they do not work well with lowquality coal, as in Brazil [33,37]. Due to the high temperatures reached in the boiler, this process has a high $\mathrm{NO}_{\mathrm{x}}$ content and a significant small diameter particulate matter in the exhaust gases [38]. Adopting new technologies such as supercritical boilers can provide more than $40 \%$ efficiency with lower emissions. Supercritical plants' evolution allowed the emergence of ultra-supercritical plants that operate at even higher temperatures and pressures and with thermal efficiency greater than $50 \%$ [39].

\subsection{Supercritical and ultra-supercritical plants}

Fluidized bed combustion can be operated at atmospheric pressure or under pressurization. There is also a second characterization of these technologies: circulating beds or bubbling beds. These use low fluidization speeds so that the particles are mainly in the bed.

They are generally used in small plants of up to $25 \mathrm{MW}$, offering around $30 \%$ efficiency. Circulating beds use higher rates so that the particles are kept continuously in the exhaust gases. They are used in much larger factories and can achieve efficiencies above $40 \%$ [33]. In this technology, the solid bed is generally constituted of limestone, whose objective is to accelerate thermal exchange transfer in the process.

Therefore, it provides a sulfur reduction of up to $90 \%$, without the need for additional desulfurizers, and 70 to $80 \%$ of nitrogen due to the use of temperatures lower than the conventional spraying process, around 800 to $900^{\circ} \mathrm{C}[40,41]$. Fluidized bed combustion is a flexible electric generation technology that can be used with a wide range of fuels, including low-quality solid fuels.

There has been a significant increase in power generation from coal in the fluidized bed, although only $2 \%$ of installed capacity applies to this technology in the world [42]. Another advantage is the reduction of sulfur without loss of thermal efficiency, in addition to the possibility of the technology being implemented in existing thermoelectric plants. The pulverized combustion and fluidized bed technologies are the alternatives that present the best prospects for application in future national coal-fired power plants [37].

\subsection{Integrated gasification with combined cycle}

IGCC is a process in which the fuel is aerated with enriched air or oxygen and water vapor, producing a combustible gas. It uses the combined gas turbine cycle driven by the synthesis gas's combustion, while the exhaust gases from the gas turbine, around $500{ }^{\circ} \mathrm{C}$, generate superheated steam in a recovery boiler to drive a steam turbine [14]. The IGCC plant has high thermal efficiency, $40-45 \%$ with $50 \%$ potential, and less 
atmospheric pollution than technologies based on coal as a fuel [37].

According to Liang et al. (2013) [43], IGCC has many advantages, e.g.:

i) High thermal efficiency: the IGCC plant on the market increases net efficiency by $43.5 \%$ above coal units;

ii) Less pollution: which has $99 \%$ of the desulfurization rate and the lowest $\mathrm{NO}_{\mathrm{x}}$ emission rate, which is equal to $5 \%$ of the coal units sold;

iii) Low water consumption: represents savings of $1 / 2-2 / 3$ of the consumption of commercial coal units and;

iv) Multifunctional: it features multigeneration technology, supplies electricity, heat, carbon dioxide, and chemical material simultaneously.

Gasification is the most efficient process and may be suitable for the $\mathrm{CO}_{2}$ capture and storage process [19]. Some systems have a capture efficiency between $85-96 \%$, which results in a $64-78 \%$ reduction in net greenhouse gas emissions. An estimate that regardless of whether CCS processes can reduce $\mathrm{CO}_{2}$ by $90 \%$ of gaseous effluent, the implementation of CCS technologies in power plants using fossil fuels can reduce $\mathrm{CO}_{2}$ emissions by $60-80 \%$ over the life of the process [44].

As of 2050, IGCC technologies have become a viable and environmentally attractive technological option. However, they still depend on reducing investment costs to be viable in the long run [26]. The shift in trend from existing technologies to new zero-emission technologies means that carbon investments can become 56-82\% higher for the first technology and $27-50 \%$ higher for the second technology [45, 46].

\section{METHODOLOGY}

\subsection{Instruments of collection and information analysis}

The information collected comes from primary and secondary sources. The primary ones involved the application of questionnaires with collaborators of several hierarchical levels, semi-structured interviews, and checklist with the manager of the environment and observation in loco to identify the intrinsic characteristics to the production processes in which they refer to emerging environmental control actions. While the secondary ones referred to the documentation analysis, database of operation, and national reports of the environment. Data evaluation was carried out by triangulating the information obtained.

The questionnaire was developed taking into account the doctoral theses of the authors Giesta [47] and Souza [48], involving the evaluation of the environmental management system in companies, the proposal of a questionnaire presented by Mol et al. [49], the analyzes in the $14^{\text {th }}$ national survey on social responsibility and sustainable practices developed by the Ires Institute [50], and the diagnostic questionnaire concerning environmental education presented in the Encea document promoted by the Ministry of the Environment in 2009 [51], in addition to CONAMA Resolution 436/2011 [52], which establishes the maximum emission limits of atmospheric pollutants for fixed sources. It should be noted that all these documents were referenced at the end of the work for possible consultations.

Therefore, the questionnaire contains open and closed questions in its structure, with a predominance of the second. The answers were classified as open, dichotomous, and multiple-choice, considered most pertinent to the subject. The questions were elaborated on so as not to embarrass the interviewee. A free and informed consent form was made available to research participants, preceded by a letter of presentation and invitation that includes the institution and the course of origin of the researcher and its purpose.

The pilot questionnaire's purpose was to analyze possible flaws in the theoretical structure and arrangement of the questions to avoid possible redundancies, and this application was considered satisfactory about the research objective. Factors that could affect answers decision of the applied questionnaires were motivated due to the exchange of functions of some collaborators, signaling adaptation to these in the new function's attributions. These factors did not interfere in the research objectives since they did not cause a significant variation between the individual results attributed to the real differences between the individuals and the sector that operates in the company.

The semi-structured interviews were used to facilitate the researcher's proximity to the interviewee and collect more precise data and information. This research instrument's advantage is the flexibility attributed to the researcher, seeking more information, which could not have been found in documentary sources. Guided by some questions, the interview was directed to the manager/environmental leader of the thermoelectric plant to collect information about the projects developed and the clean technologies implemented and other questions pertinent to the research.

The organization was analyzed in its amplitude, precisely the actions related to the activities of the environmental management system related to the reduction of polluting gases in the atmosphere, part of the strategic planning prioritized, taking into account the environmental policy disseminated among the employees and the development of programs and practices that provide environmental awareness in the execution of activities

\subsection{Definition of respondent sample}

The formation of this sample was conceived randomly because the selection of respondent employees occurred entirely at random, linked only to the established days for applying the questionnaires. The schedule of weekly shifts defined among employees was respected, preventing it from being selected again in another application. The percentage of questionnaires considered in the survey corresponded to $40 \%$ of the total employees (175 employees) who worked in the thermoelectric complex, representing 70 employees. Among the participating positions, administrative assistants, and technicians in electrotechnics had the most significant research representation. Besides, we sought to identify employees' profiles by gender, age, and company time. Regarding sex, more than $75 \%$ of respondents were men. The average age was 39 years old, referring to a range of 21 to 60 years old. The average length of stay in the company was seven years. Figure 1 shows the active positions that participated in the research. 


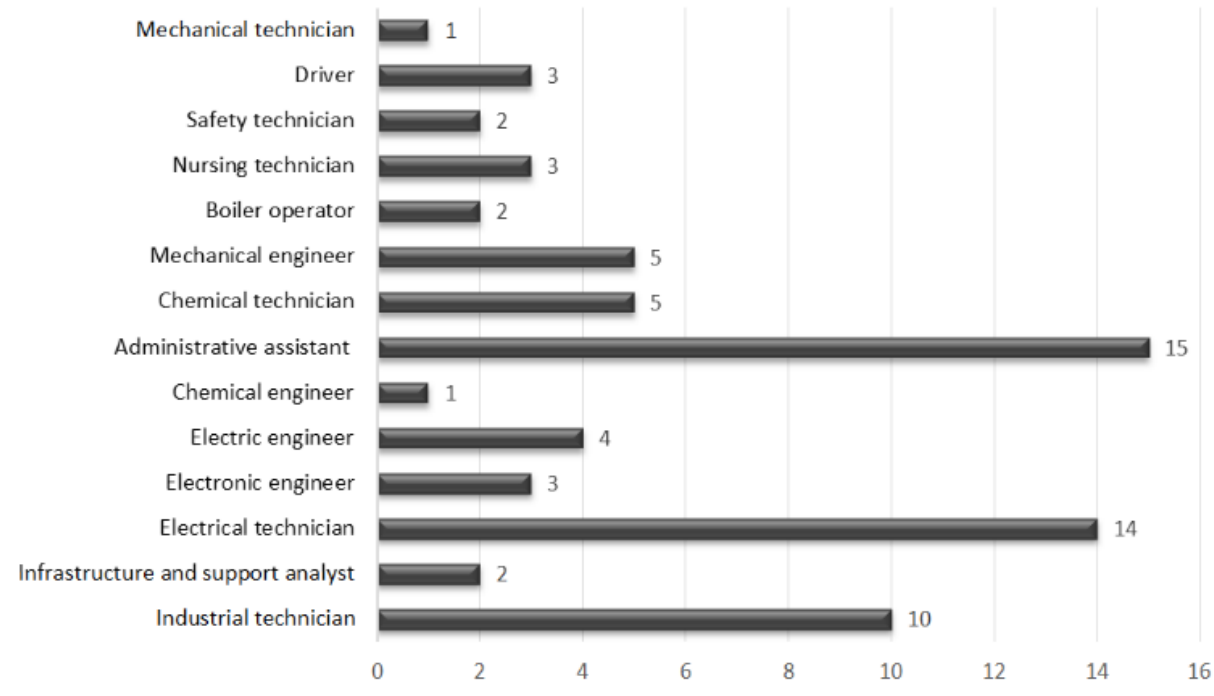

Figure 1. Professional profile in the survey

\subsection{Analytic Hierarchy Process (AHP)}

AHP is a useful tool for dealing with complex decision making that involves problems with multiple criteria and can help the decision-maker prioritize the best alternative [53]. The analysis considered a set of evaluation criteria and a set of alternatives, among which the best decision is to achieve the most appropriate trade-off between the different criteria. Peerto-peer comparison is required soon after constructing the hierarchy, expressed in verbal terms, which will be converted into numerical values using the Saaty fundamental scale for comparative judgments (Table 1).

Table 1. Saaty number range

\begin{tabular}{|c|c|c|}
\hline Scale & Def. & Obs. \\
\hline 1 & $\begin{array}{l}\text { Both elements of } \\
\text { similar importance }\end{array}$ & $\begin{array}{l}\text { Both elements contribute } \\
\text { ownership equally }\end{array}$ \\
\hline 3 & $\begin{array}{l}\text { The importance is } \\
\text { moderate }\end{array}$ & $\begin{array}{c}\text { Opinion favor one element } \\
\text { over another }\end{array}$ \\
\hline 5 & $\begin{array}{l}\text { The importance is } \\
\text { strong }\end{array}$ & $\begin{array}{l}\text { One component shows } \\
\text { higher favor }\end{array}$ \\
\hline 7 & $\begin{array}{c}\text { The importance is very } \\
\text { strong }\end{array}$ & $\begin{array}{l}\text { One component is very high } \\
\text { favored over the other }\end{array}$ \\
\hline 9 & $\begin{array}{l}\text { The importance is } \\
\text { extreme importance. }\end{array}$ & $\begin{array}{c}\text { A component is favored by } \\
\text { one order }\end{array}$ \\
\hline $\begin{array}{c}2,4,6 \\
8\end{array}$ & $\begin{array}{l}\text { The importance is } \\
\text { intermediate. }\end{array}$ & $\begin{array}{l}\text { Used as consensus values } \\
\text { for opinions }\end{array}$ \\
\hline
\end{tabular}

The judgment reflects the answers to two questions: which of the two elements is most famous for higher-level criteria and what intensity. The number of judgments necessary to complete the matrix of comparison between the criteria remains conditioned to the total of established criteria and the number of elements compared [53],

$$
\frac{n(n-1)}{2}
$$

where, $n$ is evaluated criteria number.
The consistency vector was determined from the division of each weight by its respective priority. The arithmetic mean of the consistency vector's values is equivalent to the estimate of the largest eigenvalue of $\lambda$ [54]. The consistency index (CI) for an array of size $n$ was determined by:

$$
C I=\frac{(\lambda \max -n)}{(n-1)}
$$

where, $\lambda \max$ is the eigenvector or principal vector of Eigen, and $\mathrm{n}$ is the evaluated criteria number. To obtain the consistency ratio (CR) is sufficient to divide the CI by the mean random inconsistency (MRI) index, a constant whose value depends on the size of the analyzed matrix (Table 2) [55].

The consistency ratio value is determined by the quotient between the consistency index and the mean random inconsistency, given by:

$$
C R=\frac{C I}{M R I}<0.1 \sim 10 \%
$$

The consistency of judgments considers that an acceptable value for the consistency ratio should remain less than or equal to 0.10 [56]. It is necessary to combine the comparison matrices of the alternatives with the importance matrix of the criteria, developing a global priority vector from the average local priority (LP), according to the equation to finalize the calculations [53].

$$
\begin{aligned}
& G P 1=R P(\operatorname{Cr} 1)^{*} L P(a 1) \operatorname{Cr} 1 \\
&+\cdots+R P(\operatorname{Cr} 6)^{*} L P(a 1) \operatorname{Cr} 6
\end{aligned}
$$

where,

GP1 = Global priority for alternative 1 ;

$\mathrm{RP}(\mathrm{Cr} 1)=$ Relative priority for criterion 1 ;

$\mathrm{LP}(\mathrm{a} 1) \mathrm{Cr} 1=$ Criterion 1 local priority for alternative 1 .

The alternative that presents the best global priority identifies the technology option as more accessible and compatible with the thermal plant's productive process, making it possible to minimize air pollutants' emissions.

Table 2. Random inconsistency index

\begin{tabular}{ccccccccc}
\hline Size of matrix & $\mathbf{1}$ & $\mathbf{2}$ & $\mathbf{3}$ & $\mathbf{4}$ & $\mathbf{5}$ & $\mathbf{6}$ & $\mathbf{7}$ & $\mathbf{8}$ \\
\hline Mean random inconsistency & 0.00 & 0.00 & 0.52 & 0.89 & 1.11 & 1.25 & 1.35 & 1.40 \\
\hline \multicolumn{3}{c}{ Source: Saaty, $2012[55]}$.
\end{tabular}




\section{RESULTS AND DISCUSSION}

\subsection{Operational efficiency and clean technologies associated with the energy generation process}

The combustion of the mineral coal occurs in a pulverized form, which was processed in mills to reach the required granulometry in the process. This fact substantially improves the combustion efficiency and the conversion of the thermal energy into electrical energy, maintaining $74 \%$ efficiency. The most critical environmental impacts of the burning of this fuel correspond mainly to the air emissions released during the plant's operation. Table 3 shows the technologies used in the thermoelectric plant for the treatment of gases and waste. These effluent gas treatment technologies represent the developed alternatives to reduce pollutant emissions from the thermoelectric plant. The increased efficiency of the generation plant is a better cost-benefit and faster results in reducing these emissions.

The articulation of methods aiming at emissions control of $\mathrm{SO}_{2}, \mathrm{NOx}$, and particulates are being adopted. The trend is that environmental pressures increase to the reduction of $\mathrm{CO}_{2}$. Figure 2 shows the associated technologies in the plant production process. $\mathrm{NO}_{\mathrm{x}}$ emissions are controlled directly in the combustion process.

The low-emission $\mathrm{NO}_{\mathrm{x}}$ burners ensure better control of the combustion temperature by reducing nitrogen oxidation in the combustion air. The desulfurization system adopted is of the semi-dry type and uses quicklime as a desulfurizing agent. The advantages of this process integrated with the dust collection system include the high efficiency provided that allows rates above $98 \%$ in the reduction of $\mathrm{SO}_{2}$ emissions; and $99 \%$ reduction of particulate matter (fly ash) and low water consumption without generating liquid effluents.

Table 3. Technologies for the treatment of gases and waste from the thermoelectric plant

\begin{tabular}{ccc}
\hline Environmental impacts & Treatment technologies & Maximum reduction \\
\hline & Filtration of exhaust gases & $98 \%$ \\
Particulates & Gas Washer & $99.90 \%$ \\
& Electrostatic precipitator & $99.99 \%$ \\
Sulfur Dioxide & Sleeve filter & $99.99 \%$ \\
Nitrogen Oxide & Gas desulfurization with semi-dry type absorber injection system & $>98 \%$ \\
& Temperature control & $70 \%$ \\
Mercury & Electrostatic precipitator & $42 \%$ \\
& Sleeve Filters & $82 \%$ \\
Ashes & Gas Washer & $>90 \%$ \\
& Use as building materials and civil engineering & $100 \%$ \\
\hline
\end{tabular}

Table 4. Values of measurements of inhalable particle for monitoring stations, $\left[\mu \mathrm{g} / \mathrm{m}^{3}\right]$

\begin{tabular}{ccccc}
\hline Station & \multicolumn{4}{c}{ Days under analysis } \\
\hline & $11 / 07 / 2017$ & $18 / 07 / 2017$ & $25 / 07 / 2017$ & $01 / 08 / 2017$ \\
1 & 20 & 15 & 20 & 42 \\
2 & 21 & 37 & 29 & 85 \\
3 & 23 & 23 & 24 & 32 \\
4 & 18 & 17 & 16 & 30 \\
5 & 19 & 16 & 20 & 32 \\
CONAMA 03/1990 & \multicolumn{5}{c}{150} \\
\hline
\end{tabular}

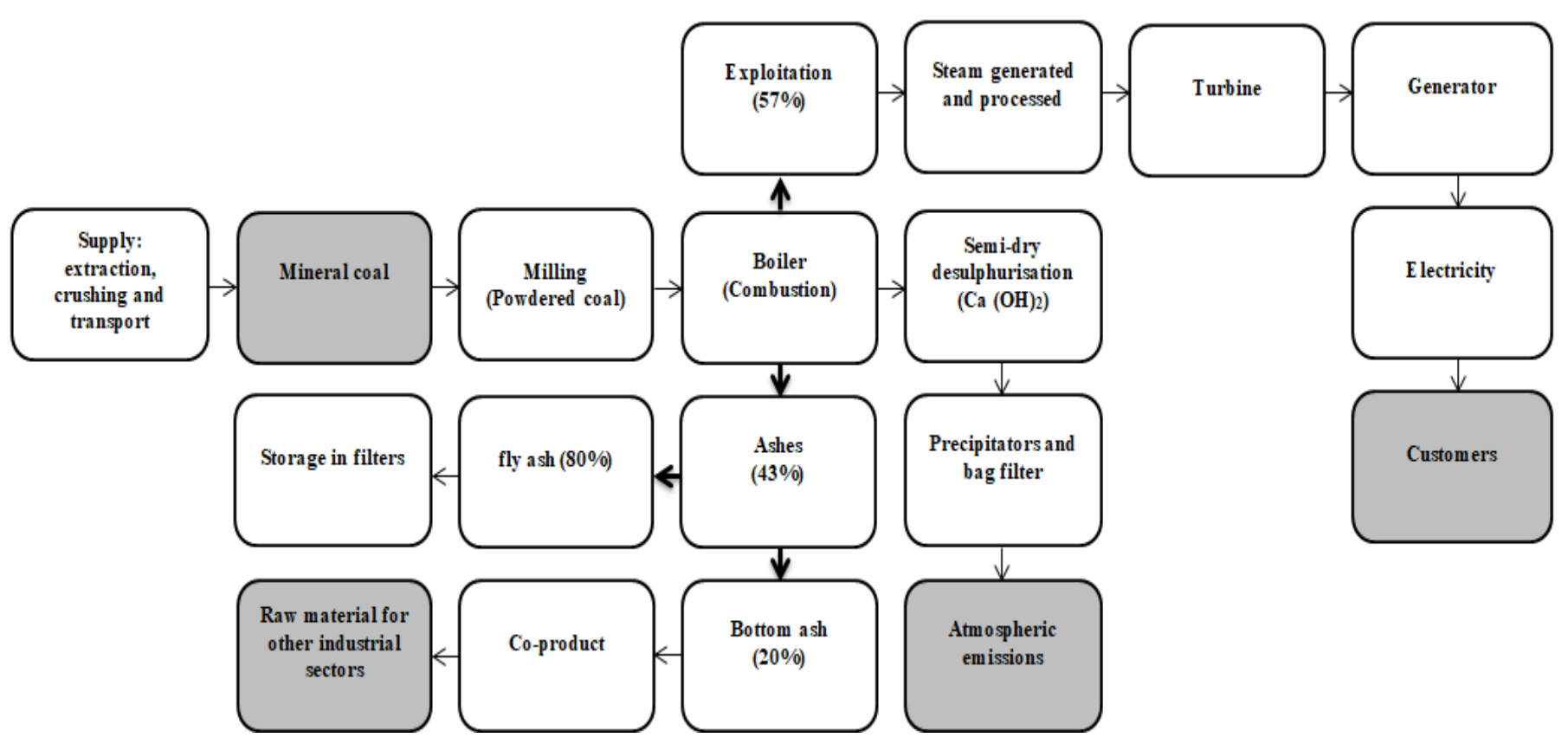

Figure 2. Simplified diagram of energy production, indicating the technologies associated to the process 
Coal ashes were produced in the boiler as waste. At about $80 \%$ of the ash, mineral residues resulting from the burning of the light-type coal were drawn through the air and combustion gas circuit, entering the electrostatic filters, where it was captured to meet the emission standard established in the environmental licensing process. The heavy ashes, which account for $20 \%$ of the total ash, fall into the steam-generating furnace's bottom, inside a hopper with water, where it is cooled for subsequent extraction.

The light ash is collected by electrostatic precipitators and transported pneumatically to the storage silos for later transport to other industrial sectors, used as raw material. The heavy ashes are removed from the furnace by its base, falling into tanks with cooling water, and are removed by hydraulic drag to the settling basins. Sedimented, they can be removed for use.

Particulate matter emissions can be minimized by using good combustion and design practices. Electrostatic precipitators extract particulate material from flue gases through the ionization process. In these, the gray particles are electrostatically charged with a negative charge and are thus attracted by positively charged collector plates. The removal of particles adhered to the plates occurs through a mechanical tapping system.

Thus, it was noted that the large production of solid waste, including light and heavy ash, is intrinsic to the production process. Sediments from the liquid effluent treatment system and eventual residues in fuel preparation make up solid residues on a smaller scale. However, to minimize these effects, the plant maintains these residues' management, carrying out the treatment and proper destination and prioritizing, whenever possible, reuse.

\subsection{Environmental management system under an environmentally sustainable model}

Equipment for continuous monitoring of atmospheric emissions was installed to control compliance with emission standards. It was also surveyed the levels of inhalable particles, through automatic stations, full time in the region, and weekly in the main urban centers, with results that meet the air quality standard defined by CONAMA 03/1990 [57]. The analysis points of the air quality, rain quality, and meteorological conditions monitoring network, installed in the region of influence of the thermoelectric complex, a total of five automatic stations.

Besides, it maintains the monitoring of four internal points, facilitating the availability of access to the discharge point for the periodic verification of emissions to certify that the requirements established by CONAMA Resolution 436/2011 [52] are being met. Control is maintained 24 hours digitally at the four internal points, with an average equivalent to each measured variable every hour.

If an infraction is detected within the required limits, the immediate command comprises the load reduction until the leading cause is found. The monitoring and control of atmospheric pollutants have appropriate measuring equipment, and the maintenance and calibration records of the gas measuring equipment are kept monthly, and those of particulate materials quarterly, maintaining preventive maintenance and, in emergency cases, corrective.

\subsubsection{Environmental Policy}

The environmental policy, defined using a multidisciplinary corporate meeting, maintains the integrated alignment in maintaining a systematic and continuous process of improvement in management practices, especially in the area of power generation. To this end, the thermoelectric develops its operations, controlling the principles of sustainability and promotes conducts with the community to ensure a conscious use of the natural resources available in the locations that integrate the plant's performance.

Among the principles, compliance with public policies, relevant legal and regulatory frameworks, as well as with international agreements to which Brazil is a signatory, stands out; ensure the maintenance of a systematic and continuous process of improvement in management practices, as well as the incorporation of the environmental dimension in production processes, implement environmental programs and actions in conjunction with other sectors and explore the potential of local and regional energy resources, taking into account to the principles of sustainable development.

Together with its sustainability policy, the greenhouse gas emissions inventory presents a diagnosis of the origin of the emissions, the quantity emitted in a given period, and the causes that result in the atmosphere, allowing the organization to establish strategies for the reduction and management of these gases. In addition to greenhouse gas emissions, atmospheric emissions of $\mathrm{SO}_{\mathrm{x}}, \mathrm{NO}_{\mathrm{x}}$ and particulate matter based on information on mineral coal consumption are also presented.

It was possible to monitor the indexes maintained over four days for a month to check the monitoring stations' measurements for inhalable particles, maintaining the frequency of weekly analysis. These particles are substances suspended in the atmosphere, considered one of the most severe pollutants in terms of consequences for public health because it affects more significantly more people in a more extended period of exposure. Table 4 lists the concentrations of inhalable particles expressed in micrograms per cubic meter $\left(\mu \mathrm{g} / \mathrm{m}^{3}\right)$ with the acceptable limit defined by national legislation.

The comparison of the results regarding the concentrations of inhalable particles obtained through the monitoring system with that stipulated in CONAMA Resolution 03/1990 [57] revealed that in no point of analysis were concentrations that exceeded the defined standards and that the points that presented the values higher levels of inhalable particles may be associated with meteorological factors, considering the action of winds as the main factor in the dispersion of the pollutant. This monitoring process allows one to verify possible changes in pollutant concentrations, helping to minimize environmental impacts.

\subsubsection{EMS practices emerging from strategic planning}

The environmental policy is documented and transmitted to employees through internal media, evidenced by $73 \%$ of the survey respondents, who listed as positive points the efficiency and articulation concerning the environmental plan, being developed and prioritized as a factor of load reduction or shutdown of the plant if the indices required by Organs environmental agencies are not met. As a negative point, they consider having numerous challenges for its implementation, highlighting the form of information disclosure as not significant, restricted to the strategic level, adding that it should include training and lectures to deepen the knowledge on the topic. When asked whether the developed environmental policy would have influenced changes in their 
environmental attitudes outside the company, only 55\% of respondents said they had observed a greater environmental awareness concerning everyday situations, admitting that the plant does not maintain a training program in order to ensure practices based on environmental issues. However, more than $90 \%$ of the employees considered in the respondent sample declared that they had specific knowledge to carry out their activities without impacting the environment, with the acquired knowledge being satisfactory, mostly, about the expectation deposited. Employees signaled the sufficiency of the resources allocated to the environmental management system (EMS), considering human resources and specialized skills, organizational infrastructure, technology, and finances. According to the percentage of employees who indicate the lack of resources allocated in the EMS (36\%), the main observations comprise the resources:

i) Human resources: training and valuing employees;

ii) Infrastructure: deactivated generating units;

iii) Technological: machinery and tooling.

Figure 3 presents some quantitative data regarding the employees' responses. Communication and disclosure related to corporate governance to stakeholders are covered in all management procedures and management and administration reports, published annually. For $95 \%$ of employees, the importance attributed to environmental actions developed is medium to high, with environmental management being recognized for $85 \%$ of respondents, responsible for reducing pollution and improving the quality of the service offered, increasing operational efficiency.

Participative management creates decentralized structures, in which the cooperative relationship becomes an essential tool to overcome internal conflicts in the production processes. Considering the sample of employees, $30 \%$ indicated that they had already contributed with some suggestion for environmental management, including improvements in the control of coal burning, flow sensors, gas analysis and analytical instrumentation, sedimentation basins, containment construction of lubricating oil in some equipment, reliability of waste reduction systems, a system to soften particulates and inspection of the industrial plant.

\subsection{Application of the analytic hierarchy process}

The application of the method was conceived in four stages: to identify the accessible and compatible technological alternatives with the production process to minimize emissions of atmospheric pollutants; to propose general criteria for the hierarchical selection of technological ones; weighting the proposed criteria for each technological alternative; define a hierarchical scale, all of which satisfy a set of evaluation criteria. Figure 4 presents the structuring of the hierarchical model for the problem.

The comparison between the factors was performed through a comparison or decision matrix. The study comparison matrix can be seen in Table 5. Obtaining the PML involves making the matrices normalized, a procedure in which each cell's elements in the column are divided by the sum of the column elements. Soon after, the average of each line is determined by obtaining the priority vectors. These steps were performed for each of the criteria. It is possible to realize that no alternative is better than the others globally. The purpose is to determine a solution, a more satisfactory and not necessarily optimal alternative, in problems where multiple criteria are considered.

The same procedure was applied to calculate the consistency ratio in all matrices, maintaining consistency between judgments. In terms of the method, the most satisfactory solution was obtained by calculating each alternative's global priority.

The judgments were made, and the importance intensity was determined according to the Saaty Scale classification to fill the matrix elements outside the diagonal. In the specific case, since six criteria were considered, it determined the need for fifteen essential judgments, which were supervised by the company's environmental manager under study.



Figure 3. Employees' perception of the EMS

Table 5. Matrix of comparison between the criteria items

\begin{tabular}{cccccccc}
\hline Criteria & C1 & C2 & C3 & C4 & C5 & C6 & Relative priority \\
\hline C1 - Deployment time & 1.0 & 0.5 & 0.3 & 0.2 & 0.5 & 0.3 & 0.06 \\
C2 - Combustion efficiency & 2.0 & 1.0 & 0.5 & 0.3 & 0.5 & 0.3 & 0.09 \\
C3 - Support operations & 3.0 & 2.0 & 1.0 & 0.3 & 2.0 & 0.5 & 0.16 \\
C4 - Cost of investment & 5.0 & 3.0 & 3.0 & 1.0 & 3.0 & 2.0 & 0.35 \\
C5 - Cost of maintenance & 2.0 & 2.0 & 0.5 & 0.3 & 1.0 & 0.5 & 0.12 \\
C6 - Greenhouse gas emissions & 3.0 & 3.0 & 2.0 & 0.5 & 2.0 & 1.0 & 0.23 \\
Total & 16.0 & 11.5 & 7.3 & 2.7 & 9.0 & 4.7 & 1.00 \\
\hline
\end{tabular}




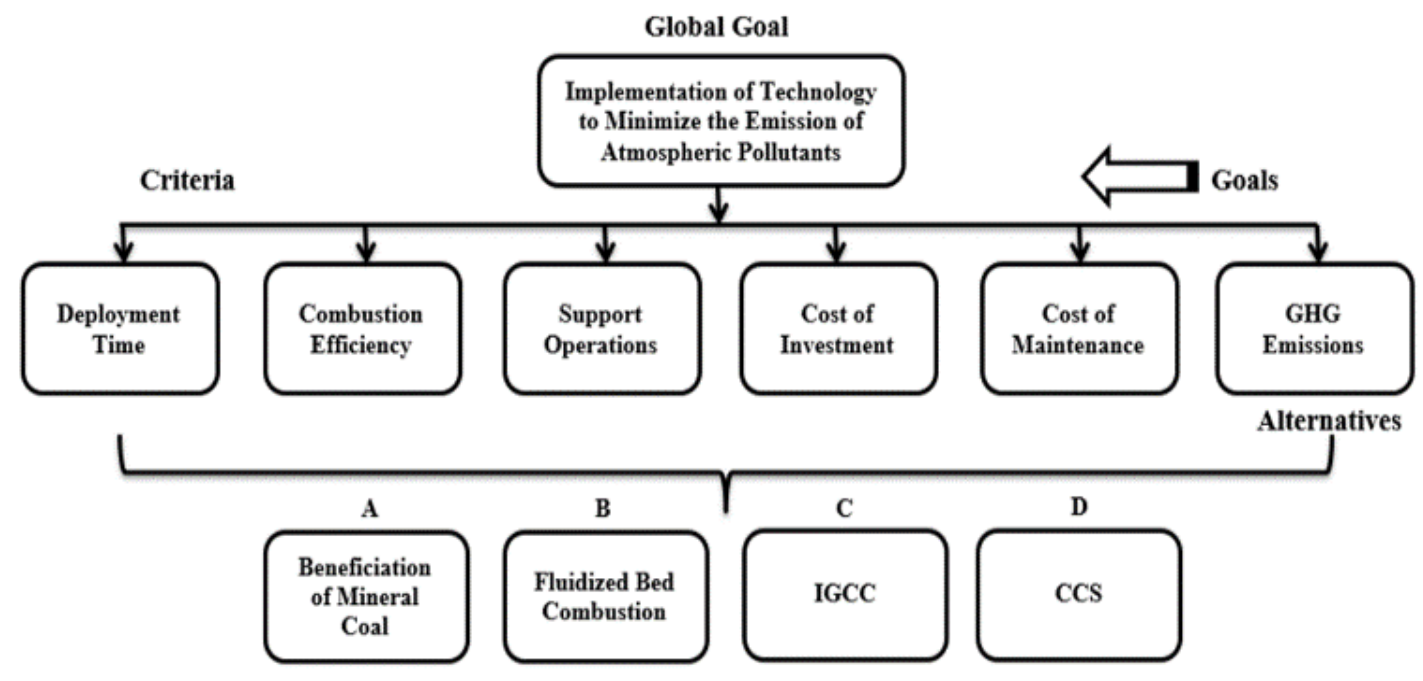

Figure 4. Hierarchical model for detailed structuring the problem

Table 6. Values for the comparison of the pairs of each criteria

\begin{tabular}{|c|c|c|c|c|c|}
\hline \multirow{2}{*}{ Criteria 1} & $\mathbf{A}$ & B & $\mathbf{C}$ & D & \multirow{2}{*}{$\mathbf{L P}$} \\
\hline & \multicolumn{4}{|c|}{ Deployment time } & \\
\hline $\mathrm{A}-$ - Beneficiation of mineral coal & 1 & 2 & 3 & 3 & 0.435 \\
\hline B - Fluidized bed combustion & $1 / 2$ & 1 & 3 & 3 & 0.309 \\
\hline C-Gasification with combined cycle & $1 / 3$ & $1 / 3$ & 1 & 2 & 0.150 \\
\hline D -Capture of carbon and storage & $1 / 3$ & $1 / 3$ & $1 / 2$ & 1 & 0.106 \\
\hline Criteria 2 & \multicolumn{4}{|c|}{ Combustion efficiency } & \\
\hline A - Beneficiation of mineral coal & 1 & $1 / 2$ & $1 / 4$ & 2 & 0.143 \\
\hline B - Fluidized bed combustion & 2 & 1 & $1 / 3$ & 3 & 0.239 \\
\hline C-Gasification with combined cycle & 4 & 3 & 1 & 4 & 0.525 \\
\hline D -Capture of carbon and storage & $1 / 2$ & $1 / 3$ & $1 / 4$ & 1 & 0.093 \\
\hline Criteria 3 & \multicolumn{4}{|c|}{ Support operations } & \\
\hline A - Beneficiation of mineral coal & 1 & $1 / 2$ & 2 & 2 & 0.275 \\
\hline B - Fluidized bed combustion & 2 & 1 & 2 & 2 & 0.388 \\
\hline C-Gasification with combined cycle & $1 / 2$ & $1 / 2$ & 1 & 2 & 0.198 \\
\hline D -Capture of carbon and storage & $1 / 2$ & $1 / 2$ & $1 / 2$ & 1 & 0.139 \\
\hline Criteria 4 & \multicolumn{4}{|c|}{ Cost of investment } & \\
\hline A - Beneficiation of mineral coal & 1 & 2 & 4 & 4 & 0.479 \\
\hline B - Fluidized bed combustion & $1 / 2$ & 1 & 3 & 3 & 0.294 \\
\hline C-Gasification with combined cycle & $1 / 4$ & $1 / 3$ & 1 & $1 / 2$ & 0.093 \\
\hline D -Capture of carbon and storage & $1 / 4$ & $1 / 3$ & 2 & 1 & 0.134 \\
\hline Criteria 5 & \multicolumn{4}{|c|}{ Cost of maintenance } & \\
\hline A - Beneficiation of mineral coal & 1 & 2 & 3 & 3 & 0.435 \\
\hline B - Fluidized bed combustion & $1 / 2$ & 1 & 3 & 3 & 0.309 \\
\hline C-Gasification with combined cycle & $1 / 3$ & $1 / 3$ & 1 & $1 / 2$ & 0.106 \\
\hline D -Capture of carbon and storage & $1 / 3$ & $1 / 3$ & 2 & 1 & 0.150 \\
\hline Criteria 6 & \multicolumn{4}{|c|}{ Greenhouse gas emissions } & \\
\hline A - Beneficiation of mineral coal & 1 & $1 / 3$ & $1 / 3$ & $1 / 4$ & 0.086 \\
\hline B - Fluidized bed combustion & 3 & 1 & $1 / 2$ & $1 / 3$ & 0.177 \\
\hline C-Gasification with combined cycle & 3 & 2 & 1 & $1 / 3$ & 0.242 \\
\hline D -Capture of carbon and storage & 4 & 3 & 3 & 1 & 0.495 \\
\hline
\end{tabular}

Table 7. Values of local average priorities (LP) and global priorities (GP)

\begin{tabular}{cccccccc}
\hline \multirow{2}{*}{ Alternatives } & C1 & C2 & C3 & C4 & C5 & C6 & \multirow{2}{*}{ Global priority } \\
\cline { 2 - 7 } & \multicolumn{7}{c}{ Local average priorities } \\
A & 0.435 & 0.143 & 0.275 & 0.479 & 0.435 & 0.086 & 0.321 \\
B & 0.309 & 0.239 & 0.388 & 0.294 & 0.309 & 0.177 & 0.281 \\
C & 0.150 & 0.525 & 0.198 & 0.093 & 0.106 & 0.242 & 0.186 \\
D & 0.106 & 0.093 & 0.139 & 0.134 & 0.150 & 0.495 & 0.212 \\
\hline
\end{tabular}

For inverse comparisons, in the upper right part of the matrix, the reciprocal values of those in the lower-left part of the matrix are placed. It can be seen in the lower left that most of the line elements are more dominant than the column elements since almost all positions are with numbers greater than the unit. Each value obtained in the previous table is divided by the total of its respective column. In this way, the relative priorities of the criteria are obtained.

According to the results, it was found that the order of relative importance of the criteria corresponded to cost of the 
investment $(35.2 \%)$, emissions of greenhouse gases $(22.4 \%)$, support operations $(15.8 \%)$, cost of maintenance $(11.8 \%)$, efficiency in combustion (8.8\%), and deployment time (6\%).

It presented a consistency ratio of 0.024 , which determined that the comparisons in pairs of the criteria' comparison matrix had excellent consistency. Comparing the alternatives was structured for each criterion to maintain the comparison with the same scale of values, highlighting in the last column the average local priority of the alternatives (see Table 6).

Each criterion comparison matrix should be multiplied by the criteria priority vector table, based on this combination is the final score obtained for each alternative (Table 7). The best solution corresponded to alternative "A," which consists of investing in a coal beneficiation plant. This productive resource would increase fuel quality and, consequently, combustion efficiency, reduce the costs of grinding in the boiler operation, in the ashes circuit, and the treatment of gaseous emissions.

The investment cost was defined as the most important criterion.

\section{CONCLUSION}

The world trend, although it is of increasing the participation of renewable energy sources, coal continues to stand out as the leading world source of electric energy. The projects of supercritical and ultra-supercritical plants are in an advanced stage. However, they require great investments to make them viable. Integrated gasification with a combined cycle is a worldwide trend only for the long term; in this case, this technology is a process that can be perfectly adapted to the type of coal found in the country. Thus, these technologies play an essential role in the national and global environmental.

Most of these existing technologies in Brazil have not yet been applied and depend on gains of scale to allow cost reductions that make their implementation possible. Economic growth and protection of the environment will be the main drivers of changes in the energy sector, requiring that a large part of the new generation is carbon-free and that there is a substantial increase in the efficiency of fossil fuels. Although the path until 2025 is essentially evolutionary, from then on, the participation of new technologies should grow significantly, with the concept of sustainability guiding these changes.

The treatment technologies developed to reduce the pollutant emissions levels of the analyzed thermal power plant represent pulverized mineral coal combustion, which substantially improves the efficiency of combustion and the conversion of thermal energy into electrical energy. $\mathrm{NO}_{x}$ emissions are controlled directly in the combustion process. The semi-dry desulfurization system, which uses quicklime as a desulfurizing agent, allows rates higher than $98 \%$ to reduce $\mathrm{SO}_{2}$ emissions and $99 \%$ reduction of particulate matter, extracted from the combustion gases using electrostatic precipitators and filter of sleeves.

The comparison of the results referring to the concentrations of inhalable particles, obtained through the continuous air quality monitoring system, with the provisions of CONAMA Resolution 03/1990 [57], in the sampling period revealed that in no point of analysis were there concentrations that exceeded the defined patterns and, that the points that presented the highest values of inhalable particles can be associated with meteorological factors, considering the action of the winds as the main factor in the dispersion of the pollutant. This monitoring process assists in decision making to minimize environmental impacts.

The Analytic Hierarchy Process method verified the investment in a coal processing plant as the most accessible technology and compatible with the production process, with $32.10 \%$ of the global priority over other alternatives, contributing to increasing fuel quality and combustion efficiency. A process economically feasible must be selected that achieves a reduction in these tailings levels without an excessive loss of mineral coal and excessive capital and operating costs, providing an increase in the industrial plant's efficiency and a reduction in the gas emissions greenhouse effect.

The circumstances that lead to the adoption of clean technologies and process optimization are usually associated with continuous process industries, such as the thermoelectric plant, where the reduction of effluents can represent considerable cost savings. However, the great advantage of clean technologies lies in the possibility of reverting a wasteful cost to gains in income and productivity.

This study's main limitations refer to the lack of representativeness on the world stage, and it is not possible to generalize the results for the entire industrial sector only to the case analyzed. Despite the limitations, the research sought to contribute to adapting the thermoelectric plants operating to the clean technologies available, encouraging the application in new projects.

Suggestions for future research contemplate a technicaleconomic study of implementing the dry-process treatment to obtain a coal with lower percentages of sulfur, limestone, and mineral matter applied in the thermoelectric complex. Research with this sector can be carried out in the countries of reference to accelerate national technological development, both about the measures adopted by countries that operate old thermoelectric plants and those adopting or intending to adopt the available clean technologies

\section{REFERENCES}

[1] Estevo, J.S. (2020). China in the context of climate change: Foreign negotiations and domestic policies. Challenges, $\quad 32(1)$ : $1-27$. http://dx.doi.org/10.12804/revistas.urosario.edu.co/desa fios/a.7682

[2] Roso, V.R., Dalla, R., Martins, M.E.S., Machado, P.R.M. (2016). Fuel consumption and pollutant emissions in a diesel engine converted to ethanol for thermal generation of electric energy. Semina: Exact and Technological Sciences, 37(1): 131-142. https://doi.org/10.5433 / 16790375.2016v37n1p131

[3] Cataluña, R., Shah, Z., Venturi, V., Caetano, N.R., Silva, B.P., Azevedo, C.M.N., Silva, R., Suarez, P.A.Z., Oliveira, L.P. (2018). Production process of di-amyl ether and its use as an additive in the formulation of aviation fuels. Fuel, 228: 226-233. https://doi.org/10.1016/j.fuel.2018.04.167

[4] Brauers, H., Oei, P. (2020). The political economy of coal in Poland: Drivers and barriers for a shift away from fossil fuels. Energy Policy, 1-12. http://doi.org/10.1016/j.enpol.2020.111621

[5] He, G., Lin, J., Zhang, Y., Zhang, W., Laranjeira, G., Zhang, C., Peng, W., Liu, M., Yang, F. (2020). Enabling 
a rapid and just transition away from coal in China. One Earth, 3: 187-194. https://doi.org/10.1016/j.oneear.2020.07.012

[6] IEA. International Energy Agency. (2020). Global $\mathrm{CO}_{2}$ Emissions in 2019. https://www.iea.org/articles/globalco2-emissions-in-2019, accessed on September 7, 2020.

[7] Branco, R. (2011). Advantages and disadvantages of coal. http://www.manutencaoesuprimentos.com.br, accessed on November 9, 2017.

[8] Klein, J. (2013). Coal returns to occupy space in the electrical matrix. Jornal do Comércio, 1-10. http://jcrs.uol.com.br/site/noticia

[9] Lima, M.T.S.L., Souza, M.C. (2014). Discussing the use of thermoelectric plants in Brazil. Science and Nature, 37(1): 17-23. https://doi.org/10.5902/2179460X18493

[10] Cataluña, R., Shah, Z., Pelisson, L., Caetano, N., Da Silva, R., Azevedo, C. (2017). Biodiesel glycerides from the soybean ethylic route incomplete conversion on the diesel engines combustion process. Journal of the Brazilian Chemical Society, 28(12): 1-8. http://dx.doi.org/10.21577/0103-5053.20170100

[11] World Energy Council. (2016). World energy resources. https://www.worldenergy.org/assets/images/imported/2 016/10/World-Energy-Resources-Fullreport2016.10.03.pdf

[12] ANEEL. National Agency of Electric Energy. (2012). The process of producing electric energy from coal, 131141. http://www.aneel.gov.br, accessed on October 19 , 2017.

[13] Caetano, N.R., Figueira da Silva, L.F. (2015). A comparative experimental study of turbulent non premixed flames stabilized by a bluff-body burner. Experimental Thermal and Fluid Science, 63: 20-33. https://doi.org/10.1016/j.expthermflusci.2015.01.006

[14] Tolmasquim, M.T. (2016). Thermoelectric energy: Natural gas, biomass, mineral coal, nuclear. Energy Research Company: Rio de Janeiro, 217-318.

[15] Flores, B., Agra, A., Gums, A., Silva, G., Osório, E., Vilela, A. (2020). Thermoplastic interaction of ultra-high fluidity Brazilian coal with components of blends. Journal of Materials Research and Technology, 9(3): 2737-2743. https://doi.org/10.1016/j.jmrt.2020.01.006

[16] Caetano, N.R., Lorenzini, G., Lhamby, A.R., Guillet, V.M.M., Klunk, M.A., Rocha, L.A.O. (2020). Experimental assessment of thermal radiation behavior emitted by solid porous material. International Journal of Heat and Technology, 38(1): 1-8. https://doi.org/10.18280/ijht.380101

[17] Bertol, M.A., César, S.B., Maciel, L.A.C., Müller, A.A., Santos, H.M., Schmitt, J.C.C. (1987). Analytical Profile of Coal. 2 ed. Porto Alegre: National Department of Mineral Production, 2, p. 140.

[18] Freitas, D.V. (2012). Organic geochemical study of the stratigraphic profile of fossil coal from Candiota, RS, Brazil. Master's dissertation in chemistry, Federal University of Rio Grande do Sul, p. 66.

[19] Domenico, M.D. (2013). Gasification of Brazilian mineral coal in the presence of lithium orthosilicate in order to increase the production of hydrogen. $\mathrm{PhD}$ thesis in chemical engineering, Federal University of Santa Catarina, p.198.

[20] Brazil. Energy research company, 2018. National Energy Balance 2018, base year 2017: Summary Report. Rio de Janeiro: Ministry of Mines and Energy. Available at: http://www.epe.gov.br/en/publicacoes-dadosabertos/publicacoes/balanco-energetico-nacional-2018, accessed on May 06, 2019.

[21] Fraga, A., Klunk, M.A., Oliveira, A., Furtado, G., Knornschild, G.H., Dick, L.F.P. (2014). Soil corrosion of the AISI1020 steel buried near electrical power transmission line towers. Materials Research, 17(6): 1637-1643. https://doi.org/10.1590/1516-1439.305714

[22] Klunk, M.A., Das, M., Dasgupta, S., Impiombato, A.N., Caetano, N.C., Wander, P.R., Moraes, C.A.M. (2020). Comparative study using different external sources of aluminum on the zeolites synthesis from rice husk ash. Materials Research Express, 7(1): 015023. https://doi.org/10.1088/2053-1591/ab608d

[23] Caetano, N.R., Cataluña, R., Vielmo, H.A. (2015). Analysis of the effect on the mechanical injection engine using doped diesel fuel by ethanol and bio-oil. International Review of Mechanical Engineering, 9: 124128. https://doi.org/10.15866/ireme.v9i2.4341

[24] IEA. International Energy Agency. (2015). Key electricity trends Excerpt from: electricity information. Available at: http://www.iea.org/publications.html, accessed on January 6, 2017.

[25] Licks, L.A., Pires, M. (2010). Methodology for the calculation of carbon emissions and the efficiency in the generation of energy by combustion of fossil coal in Brazil. Magazine School of Mines, 63(2): 331-337.

[26] IEA. International Energy Agency. (2012). Technology Roadmap: High-Efficiency, Low-Emissions Coal-Fired Power Generation. Available at: http://www.iea.org/publications.html, accessed on January 6, 2017.

[27] Klunk, M.A., Shah, Z., Caetano, N.R., Conceição, R.V., Wander, P.R., Dasgupta, S., Das, M. (2020). $\mathrm{CO}_{2}$ sequestration by magnesite mineralization through interaction between $\mathrm{Mg}$-brine and $\mathrm{CO}_{2}$ : integrated laboratory experiments and computerized geochemical modelling. International Journal of Environmental Studies, $77(3)$ : 492-509. https://doi.org/10.1080/00207233.2019.1675295

[28] Ruoso, A.C., Lhamby, A., Missaggia, A.B., Klunk, M.A., Caetano, N.R. (2020). Energetic and economic analysis of use of hydrated ethanol. Periódico Tchê Química, 17(34): 220-239.

[29] Fasihi, M., Efimova, O., Breyer, C. (2019). Technoeconomic assessment of $\mathrm{CO}_{2}$ direct air capture plants. Journal of Cleaner Production, 224: 957-980. https://doi.org/10.1016/j.jclepro.2019.03.086

[30] Klunk, M.A., Dasgupta, S., Das, M., Wander, P.R. (2019). Computer codes of geochemical modeling used to water-rock interaction simple and complex systems. Periódico Tchê Química, 16(32): 108-118.

[31] Rashid, A., Asif, F.M.A., Krajnik, P., Nicolescu, C.M. (2013). Resource conservative manufacturing: An essential change in business and technology paradigm for sustainable manufacturing. Journal of Cleaner Production, 57: 166-177. https://doi.org/10.1016/j.jclepro.2013.06.012

[32] Marchionni, M., Bianchi, G., Tsamos, K.M., Tassou, S.A. (2017). Techno-economic comparison of different cycle architectures for high temperature waste heat to power conversion systems using $\mathrm{CO}_{2}$ in supercritical phase. Energy Procedia, 123: 305-312. https://doi.org/10.1016/j.egypro.2017.07.253 
[33] Oliveira, E.A. (2009). Perspectives of thermelectric generation of coal in Brazil in horizon 2010-2030. Master's dissertation in energy planning, Federal University of Rio de Janeiro, p. 155.

[34] IEA. International Energy Agency. (2009). Clean Coal Centre. Available at: http://www.iea-coal.co.uk, accessed on February 6, 2017.

[35] Ruoso, A.C., Bittencourt, L.C., Sudati, L.U., Klunk, M.A., Caetano, N.R. (2019). New parameters for the forest biomass waste Eco firewood manufacturing process optimization. Periódico Tchê Química, 16(32): 560-571.

[36] EPE. Energy Research Company. (2007). Thermoelectric Generation, Coal Mineral. National Energy Plan 2030, Chapter 6, Brasília: Ministry of Mines and Energy.

[37] Silva, D.C. (2016). Comparative thermoeconomic analysis of advanced cycles from thermoelectric plants to coal and thermonuclear plants. $\mathrm{PhD}$ thesis in mechanical engineering, Federal University of Itajubá, p. 213.

[38] Shah, Z., Veses, R.C., Brum, J., Klunk, M.A., Rocha, L.A.O., Missaggia, A.B., de Oliveira, A.P., Caetano, N.R. (2020). Sewage sludge bio-oil development and characterization. Inventions, 5(3): 36-46. https://doi.org/10.3390/inventions5030036

[39] Gavronski, J.D. (2007). Mineral coal and renewable energy in Brazil. $\mathrm{PhD}$ thesis in mining, metallurgical and materials engineering, Federal University of Rio Grande do Sul, p. 290.

[40] Romano, M.C., Lozza, G.G. (2010). Long-term coal gasification-based power with near-zero emissions. Part B: Zecomag and oxy-fuel IGCC cycles. International Journal of Greenhouse Gas Control, 4(3): 469-477. https://doi.org/10.1016/j.ijggc.2009.11.010

[41] CEMIG. Companhia Energética de Minas Gerais. (2012). Energy Alternatives: a Cemig vision. Belo Horizonte.

[42] Wander, P.R., Bianchi, F.M., Caetano, N.R., Klunk, M.A., Indrusiak, M.L.S. (2020). Cofiring low-rank coal and biomass in a bubbling fluidized bed with varying excess air ratio and fluidization velocity. Energy, 203: 117882. https://doi.org/10.1016/j.energy.2020.117882

[43] Liang, D., Xing, X., Shen, W. (2013). Technical and economic evaluation of china's integrated gasification combined cycle: The case of Yantai project. Low Carbon Economy, 4(3):

117-124. https://doi.org/10.4236/lce.2013.43012

[44] Singh, B., Stromman, A.H., Hertwich, E.G. (2011). Comparative life cycle environmental assessment of CCS technologies. International Journal of Greenhouse Gas Control, 5(4): 911-921. https://doi.org/10.1016/j.ijggc.2011.03.012

[45] Guo, Y., Huang, Z., Zhou, Z. (2015). Technology roadmap of IGCC industry in China. Energy and Power
Engineering,

$7(11):$

$535-545$

https://doi.org/10.4236/epe.2015.711050

[46] Caetano, N.R., Silva, B.P. (2017). Technical and economic viability for briquettes manufacture. Defect and Diffusion Forum, 380: 218-226. https://doi.org/10.4028/www.scientific.net/DDF.380.21 8

[47] Giesta, L.C. (2009). Environmental education and environmental management system in companies. $\mathrm{PhD}$ thesis in administration, Federal University of Rio Grande do Sul, p. 147.

[48] Souza, M.A.B. (2010). Evaluation model of knowledge management activities in the environmental management system. $\mathrm{PhD}$ thesis in engineering and knowledge management, Federal University of Santa Catarina, p. 295.

[49] Mol, M.P.G., Santos, E.S., Nunes, I.S. (2013). Proposal of a questionnaire for auditing companies of waste incineration of health service. IV brazilian congress on environmental management, 01-08, Salvador. Brazilian Institute of Environmental and Sanitation Studies. Salvador: ConGeA.

[50] IRES. Institute Association of Sales and Marketing Directors of Brazil of social responsibility. (2013). 14 ${ }^{\text {th }}$ National Survey on Social Responsibility and Sustainable Practices in companies.

[51] ENCEA. National Strategy for Communication and Environmental Education. (2009). National System of Conservation Units. Brasília: Ministry of Mines and Energy.

[52] CONAMA. National Council for the Environment. (2011). Resolution $n^{\circ} 436$, of December 22. It establishes the emission ceilings for atmospheric pollutants to installed fixed sources or installation license application prior to January 2, 2007. Available at: http://www.mma.gov.br, accessed on June 26, 2017.

[53] Saaty, T.L. (1980). The Analytic Hierarchy Process. New York: McGraw-Hill.

[54] Saaty, R.W. (1987). The analytic hierarchy process: what is it and how is it used. Mathematical Modeling, 9(3-5): 161-176. https://doi.org/10.1016/0270-0255(87)90473-8

[55] Saaty, T.L. (2012). Decision Making for Leaders: The Analytic Hierarchy Process for Decisions in a Complex World. 3rd Revise ed. Pittsburgh, PA: RWS Publications.

[56] Saaty, T.L. (1990). How to make a decision: The analytic hierarchy process. European Journal of Operational Research, 48(1): 9-26. https://doi.org/03772217(90)90057-I

[57] CONAMA. National Council for the Environment. (1990). Resolution $n^{\circ}$ 03, of June 28. Provides for air quality standards, foreseen in PRONAR. Available at: http://www.mma.gov.br, accessed on June 26, 2017. 